\title{
Predicting death in young offenders: a retrospective cohort study
}

\author{
Carolyn Coffey, Rory Wolfe, Andrew W Lovett, Paul Moran, Eileen Cini and George C Patton
}

W e recently reported very high death rates among young offenders in Victoria, Australia. ${ }^{1}$ The overall age-adjusted standardised mortality ratio was estimated to be 9.4 for males and 41 for females. These standardised mortality ratios were higher than those in groups of comparable age with schizophrenia or eating disorders. Furthermore, the cohort of offenders contributed 12\% of all Victorian drug-related deaths.

Social adversity is common in this group, $, 2,3$ often accompanied by early offending, psychiatric disorder, substance misuse and self-harming behaviour; ${ }^{4-8}$ these factors predispose to high risk of death. Indigenous young people and those of Asian background are consistently over-represented in custody, ${ }^{9,10}$ and have characteristically high rates of psychiatric disorder ${ }^{11}$ and drug offences, ${ }^{10}$ respectively; these may be identifiable groups at increased risk of early death. ${ }^{12}$

We extended the original mortality cohort study by ascertaining additional deaths between 2000 and early 2003 with a view to identifying predictors of death using data collected routinely by juvenile justice organisations.

\section{METHODS}

\section{Study population: offender cohort}

The term "young offender" denotes a person who had received a custodial sentence by the age of 20 years. All adolescents who received their first custodial sentence in the state of Victoria between 1 January 1988 and 31 December 1999 were identified. To ensure the cohort comprised all those receiving their first custodial sentence within the study period, we included only individuals aged under 15 years on 1 Janu-

\section{ABSTRACT}

Objective: To examine predictors of death in young offenders who have received a custodial sentence using data routinely collected by juvenile justice services.

Design: A retrospective cohort of 2849 (2625 male) 11-20-year-olds receiving their first custodial sentence between 1 January 1988 and 31 December 1999 was identified.

Main outcome measures: Deaths, date and primary cause of death ascertained from study commencement to 1 March 2003 by data-matching with the National Death Index; measures comprising year of and age at admission, sex, offence profile, any drug offence, multiple admissions and ethnic and Indigenous status, obtained from departmental records.

Results: The overall mortality rate was 7.2 deaths per 1000 person-years of observation. Younger admission age (hazard ratio $[\mathrm{HR}], 1.4 ; 95 \% \mathrm{Cl}, 1.0-1.9)$, repeat admissions (HR, $1.8 ; 95 \% \mathrm{Cl}, 1.1-2.9)$ and drug offences $(\mathrm{HR}, 1.5 ; 95 \% \mathrm{Cl}, 1.0-2.1)$ predicted early death. The role of ethnicity/Aboriginality could only be assessed in cohort entrants from 1996 to 1999. The Asian subcohort showed higher risk of death from drug-related causes (HR, $2.5 ; 95 \% \mathrm{Cl}, 1.1-5.5)$, more drug offences (relative risk ratio [RRR], 13; 95\% Cl, 8.5-20.0) and older admission age (oldest group v youngest: RRR, 9.3; 95\% Cl, 1.3-68.0) than nonIndigenous Australians. Although higher mortality was not identified in Indigenous Australians, this group was more likely to be admitted younger (oldest $v$ youngest: RRR, $0.31 ; 95 \% \mathrm{Cl}, 0.15-0.63$ ) and experience repeat admissions (RRR, 1.6; 95\% Cl, 1.0-2.4).

Conclusions: Young offenders have a much higher death rate than other young Victorians. Early detention, multiple detentions and drug-related offences are indicators of high mortality risk. For these offenders, targeted healthcare while in custody and further mental healthcare and social support after release appear essential if we are to reduce the mortality rate in this group.

MJA 2004; 181: 473-477 ary 1988 (ie, those under the minimum mandated age for detention at study inception). Although data were only collected on those entering the cohort aged up to 20 years, mortality follow-up continued until 1 March 2003 (when individuals might be aged up to 30 years), thus covering a period generally well beyond the index custodial sentence.

Identification of the offender cohort has been described previously. ${ }^{1}$ The cohort was identified through two data sources depend-

\section{FOR EDITORIAL COMMENT, SEE PAGE 469}

Centre for Adolescent Health, Murdoch Children's Research Institute, Melbourne, VIC.

Carolyn Coffey, BSc, GradDipEpi, Epidemiologist; Andrew W Lovett, FRACP, Paediatrician; Eileen Cini, BSc(Hons), Research Assistant; George C Patton, MD, FRANZCP, Professor Adolescent Research.

Department of Epidemiology and Preventive Medicine, Monash University and

The Alfred Hospital, Melbourne, VIC.

Rory Wolfe, PhD, Statistician.

Health Services Research Department, Institute of Psychiatry, London, UK.

Paul Moran, MD, MRCPsych, Psychiatrist.

Reprints will not be available from the authors. Correspondence: Ms Carolyn Coffey, Centre for Adolescent Health, Murdoch Children's Research Institute, 2 Gatehouse Street, Parkville, VIC 3052 carolyn.coffey@rch.org.au ing on age at admission. Young offenders aged 15-16 years at the time of sentencing (1988-1992), then, after a change in legislation in April 1992, those aged 10-16 years were placed on statutory custodial orders for supervision by the juvenile justice section of the Victorian Department of Human Services. In Victoria, a dual-track custodial sentencing system exists, so that offenders aged 17-20 years can serve their custodial sentence in either a juvenile justice centre or an adult prison (managed by the adult corrections section of the Victorian Department of Justice) at the sentencing court's discretion. We obtained 2401 unique records for distinct individuals who were from juvenile justice and 740 from adult corrections institutions. The two sets of records were combined and duplicate data for the same individuals were identified and combined.

The cohort consisted of 2849 offenders (2625 male), minimum age 11 years. Median age at first detention for males was 17.9 years (interquartile range, 16.6-19.0 years) and, for females, 18.4 years (inter- 


\begin{tabular}{lcc}
1 Number of deaths and death rates in 19949 & person-years of observation \\
(PYO) in a cohort of 2849 young offenders & No. of deaths & Rate per 1000 PYO (95\% Cl) \\
\multicolumn{1}{l}{ All causes } & 143 & $7.2(6.1-8.4)$ \\
Substance related & 65 & $3.3(2.6-4.2)$ \\
Suicide/self-inflicted injury & 34 & $1.7(1.2-2.4)$ \\
Non-intentional injury & 29 & $1.5(1.0-2.1)$ \\
Homicide/probable homicide & 4 & $0.2(0.1-0.5)$ \\
Medical & 6 & $0.3(0.1-0.7)$ \\
Cause not known & 5 & -
\end{tabular}

Note: Medical causes of death were diseases of the circulatory system (1), infectious diseases (2), neoplasms (2), poorly defined illness (1). quartile range, 16.7-19.4 years). The median total follow-up time for males was 6.3 years; for females this was only 4.6 years, as $46 \%$ of males had entered by the end of 1995, whereas $46 \%$ of females had entered by the end of 1997.

Information on deaths was obtained by record linkage with the National Death Index, a database at the Australian Institute of Health and Welfare containing records of all deaths in Australia since 1980. Data are obtained from the Registrars of Births, Deaths and Marriages in each state and territory. Linkage was based on the client's identifying information (surname, other names, aliases, sex, date of birth, date of last contact, postcode and state of residence, country of birth). Leading cause of death was described by ICD-9 (International classification of diseases, ninth revision) code $^{13}$ for deaths occurring before 1999 or ICD-10 (International classification of diseases, tenth revision) code ${ }^{14}$ from 1999. The Victorian coroner provided the leading cause of death for 39 deaths identified by the National Death Index, but for which no cause was recorded.

Based on the coroner's assessment of intent, deliberate drug overdose was classified as suicide, while all other deaths involving the use of drugs were classified as "drug related" to establish mutually exclusive categories.

\section{Putative explanatory measures}

Although deaths were identified between 1 January 1988 and 1 March 2003, measurement of covariates was restricted to the period of cohort identification (ie, 1 January 1988 to 31 December 1999). Measures were:

Year of admission, stratified into three equal periods: 1988-1991, 1992-1995, 19961999.
Age at admission, stratified into three agegroups: $10-14$ years (4\% of males, $3 \%$ of females), $15-17$ years (48\% of males, $41 \%$ of females) and $18-20$ years (48\% of males, $56 \%$ of females).

Sex. Recorded directly from the records.

Offence profile. Records of offences were collated for each offender cumulatively, and were classified according to the Australian Standard Offence Classification divisions ${ }^{15}$ and categorised hierarchically as follows:

1. Violent offence: interpersonal violence, including firearms and violent sexual offences and incest (1662; 1544 males [59\%], 118 females [53\%]).

2. Property offence: without violent offences (888; 815 males [31\%], 73 females [33\%]).

3. Other offence: eg, against justice procedures, deception, public order, vehicle offences, but no violent or property offences (198; 172 males [7\%], 26 females [12\%]).

4. Drug offence only: (62; 55 males [2\%], 7 females [3\%]).

Individuals with no offences recorded (39 males [1.5\%], no females) were deemed missing.

Any drug offence was identified and classified separately. These occurred within the hierarchical categories: 35\% of "violent", $28 \%$ of "property", 29\% of "other" and $100 \%$ of "drug offence only". (946; 835 males [32\%], 111 females [50\%].)

Multiple admissions were identified by interpreting the data describing movement within the juvenile justice and adult corrections facilities. We identified 1097 individuals with only one admission between 1988 and 1999 (996 males [38\%], 101 females [45\%]), 723 who were readmitted (658 males [25\%], 65 females [29\%]), but we could not unequivocally classify 1029 indi- viduals (971 males [37\%], 58 females [26\%]). This last category displayed evidence of movement between juvenile justice facilities, but it was unclear if this was transfer in the course of a single sentence, escape and readmission, or readmission. These were classified as "possible readmission".

Ethnic and Indigenous status. The juvenile justice and adult corrections systems collected different information, which we combined to determine ethnicity and Indigenous status. In the juvenile justice system, ethnicity was self-identified, while, in the adult corrections system, the offender's country of birth was recorded. Indigenous status was self-identified in both systems. Completed records before 1996 were sparse. Of the 1592 offenders admitted between 1996 and 1999, 1104 self-identified as Australian or were born in Australia, including 128 Indigenous Australians. Small group numbers necessitated classifying the remaining individuals into the following categories:

- those identifying with or born in an English-speaking country (34); those with insufficient information (91 "non-Indigenous" and 14 with no information) were included in the "non-Indigenous Australian" category;

- those identifying with or born in South East Asia, China and Southern Asia were classified as "Asian" (221);

- those identifying with or born in other non-English-speaking countries were classified accordingly (128).

Ethical approval was obtained from the Royal Children's Hospital, the Victorian departments of human services and justice and the Australian Institute of Health and Welfare.

\section{Statistical analysis}

We analysed the data using Stata software, ${ }^{16}$ and compared mortality rates between subgroups using Cox proportional hazards models (survival analysis) with time from date of first admission to death or to censoring at the end of follow-up. We performed comparisons among subgroups defined by ethnic/Indigenous status using multinomial logistic regression with non-Indigenous Australian as the reference category.

\section{RESULTS}

The 143 deaths in the offender cohort correspond to a crude mortality rate of 7 deaths per 1000 person-years of observation (PYO) 
2 Estimated mortality rates per 1000 person-years of observation (PYO) and hazard ratios for all-cause mortality in 2849 young offenders

\begin{tabular}{|c|c|c|c|c|c|}
\hline Factor & $\begin{array}{l}\text { No. of } \\
\text { offenders }\end{array}$ & $\begin{array}{l}\text { No. of } \\
\text { deaths }\end{array}$ & $\begin{array}{c}\text { Mortality rate per } \\
1000 \text { PYO }\end{array}$ & $\begin{array}{c}\text { Hazard ratio } \\
(95 \% \mathrm{Cl})\end{array}$ & $P$ \\
\hline \multicolumn{6}{|l|}{ Year of first admission } \\
\hline 1988-1991 & 420 & 30 & 5.1 & 1 & \\
\hline 1992-1995 & 837 & 53 & 7.4 & $1.0(0.64-1.6)$ & 0.97 \\
\hline 1996-1999 & 1592 & 60 & 7.5 & $1.1(0.67-1.7)$ & 0.76 \\
\hline \multicolumn{6}{|l|}{ Age (years) at first admission } \\
\hline $18-20$ & 1392 & 49 & 8.1 & 1 & \\
\hline $15-17$ & 1351 & 86 & 11.2 & $1.4(0.98-2.0)$ & 0.07 \\
\hline $11-14$ & 106 & 8 & 0.7 & $1.9(0.88-3.9)$ & 0.10 \\
\hline \multicolumn{6}{|l|}{ Sex } \\
\hline Male & 2625 & 132 & 18.7 & 1 & \\
\hline Female & 224 & 11 & 1.3 & $1.2(0.64-2.2)$ & 0.59 \\
\hline \multicolumn{6}{|c|}{ Offence profile (recorded between 1988 and 1999)* } \\
\hline Violent & 1662 & 83 & 11.6 & 1 & \\
\hline Property & 888 & 48 & 6.5 & $1.1(0.74-1.5)$ & 0.78 \\
\hline Other $^{\dagger}$ & 260 & 8 & 1.5 & $0.75(0.36-1.6)$ & 0.45 \\
\hline \multicolumn{6}{|c|}{ Any drug-related offence (recorded between 1988 and 1999)* } \\
\hline None & 1864 & 86 & 14.0 & 1 & \\
\hline At least one & 946 & 53 & 5.6 & $1.5(1.0-2.1)$ & 0.03 \\
\hline \multicolumn{6}{|c|}{ No. admissions (recorded between 1988 and 1999) } \\
\hline One admission & 1097 & 31 & 6.2 & 1 & \\
\hline Known readmission & 723 & 42 & 4.7 & $1.8(1.1-2.9)$ & 0.01 \\
\hline Possible readmission & 1029 & 70 & 9.0 & $1.8(1.1-2.7)$ & 0.01 \\
\hline \multicolumn{6}{|c|}{ Ethnic/Indigenous status (applied to 1996-1999 cohort only ${ }^{\ddagger}$ ) } \\
\hline Non-Indigenous Australian & 1115 & 39 & 5.3 & 1 & \\
\hline Indigenous Australian & 128 & 6 & 0.6 & $1.3(0.56-3.1)$ & 0.53 \\
\hline Asian & 221 & 12 & 1.0 & $1.5(0.80-2.9)$ & 0.20 \\
\hline Other non-English-speaking & 128 & 3 & 0.6 & $0.66(0.20-2.1)$ & 0.49 \\
\hline
\end{tabular}

* 39 observations with no offence recorded excluded. †As only one death was recorded in the drug only offence group, this could not be analysed separately and was included in the "other" category. $\ddagger n=1592$.

3 Frequency (\%) of cause of death according to ethnic/Indigenous status in 1592 offenders admitted to custody between 1996 and 1999

\begin{tabular}{lcccc} 
Cause of death & $\begin{array}{c}\text { Non-Indigenous } \\
\text { Australian }\end{array}$ & $\begin{array}{c}\text { Indigenous } \\
\text { Australian }\end{array}$ & Asian & $\begin{array}{c}\text { Other non-English- } \\
\text { speaking }\end{array}$ \\
\hline Drug-related & $18(49 \%)$ & $2(33 \%)$ & $9(75 \%)$ & $2(67 \%)$ \\
Suicide & $11(30 \%)$ & $2(33 \%)$ & 0 & $1(33 \%)$ \\
Non-intentional injury & $7(19 \%)$ & $2(33 \%)$ & 0 & 0 \\
Other & $1(3 \%)$ & 0 & $3(25 \%)$ & 0 \\
Total & $37(100 \%)$ & $6(100 \%)$ & $12(100 \%)$ & $3(100 \%)$
\end{tabular}

(Box 1). The leading cause of death was substance related, followed by suicide and then non-intentional injury. Five recent deaths recorded by the National Death Index had no finding as to cause.

All-cause mortality rates were compared within subgroups of predictors (Box 2).
There was no evidence of a mortality difference when compared between three admission periods, the sex of the offender or offence profiles. There was weak evidence that offenders admitted under 17 years were at increased risk of death. When age group was entered as a continuous variable, the association was clearer, as average risk increased with decrease in age (hazard ratio [HR], 1.4; 95\% CI, 1.0-1.9; $P=0.030)$. Offenders with a drug-related offence, those who were readmitted and those who were possibly readmitted showed an elevated risk of death. These associations remained after adjustment for admission age group. Adjusted hazard ratios were 1.5 (95\% CI, 1.0-2.0; $P=0.035$ ) for drug-related offence, 1.7 (95\% CI, 1.0-2.7; $P=0.045$ ) for known multiple admissions, and 1.6 (95\% CI, 1.0$2.5 ; P=0.030$ ) for possible multiple admissions.

Associations between cause-specific deaths and all covariates were examined. There was clear evidence of association between drug-related death and any drugrelated offence (HR, 2.5; 95\% CI, 1.5-4.1) and Asian ethnicity versus non-Indigenous Australian status in the 1996-1999 subcohort (HR, 2.5; 95\% CI, 1.1-5.5). Being in the younger age group when admitted predicted death from non-intentional injury, with an average hazard ratio of 2.7 (95\% CI, 1.4-5.2) for decreasing age group. There was no evidence of associations between suicide and any explanatory variable.

Analysis of the effect of ethnic/Indigenous status had limited power, as only mortality in the group of offenders admitted from 1996 to 1999 could be assessed. Consequently, associations with increased risk of death from all causes in offenders of Asian birth and Indigenous offenders could neither be confirmed nor excluded.

To explore further possible associations between ethnicity/Indigenous status and death, we examined the distribution of categories within cause-of-death classifications (Box 3). Despite the lack of identifiable association with deaths from all causes, nine of the 12 deaths in the Asian group were drug-related and none were from suicide or non-intentional injury.

Possible subgroup differences were then assessed by means of multinomial logistic regression (Box 4). Compared with nonIndigenous Australians, Indigenous offenders were over-represented in the youngeradmission age groups, while the Asian offenders were over-represented in the older groups. There was marked cultural disparity in the drug-related offence patterns. Compared with non-Indigenous Australians, the risk of having a drug-related offence was increased 13-fold for Asian offenders, almost twofold for offenders from other non-English-speaking backgrounds, while Indigenous offenders showed half the risk. 


\begin{tabular}{|c|c|c|}
\hline Factor & $\begin{array}{l}\text { Relative risk ratio* } \\
\qquad(95 \% \mathrm{Cl})\end{array}$ & $P$ \\
\hline \multicolumn{3}{|l|}{ Age at admission } \\
\hline \multicolumn{3}{|l|}{$15-17$ years versus $11-14$ years } \\
\hline Non-Indigenous Australian & 1 & \\
\hline Indigenous Australian & $0.74(0.36-1.5)$ & 0.41 \\
\hline Asian & $9.1(1.2-67)$ & 0.03 \\
\hline Other non-English-speaking & $1.9(0.58-6.5)$ & 0.29 \\
\hline \multicolumn{3}{|l|}{$18-20$ years versus $11-14$ years } \\
\hline Non-Indigenous Australian & 1 & \\
\hline Indigenous Australian & $0.31(0.15-0.63)$ & 0.001 \\
\hline Asian & $9.3(1.3-68)$ & 0.03 \\
\hline Other non-English-speaking & $1.7(0.51-5.5)$ & 0.40 \\
\hline \multicolumn{3}{|l|}{ Any drug offence } \\
\hline \multicolumn{3}{|l|}{ Any versus none } \\
\hline Non-Indigenous Australian & 1 & \\
\hline Indigenous Australian & $0.58(0.38-0.88)$ & 0.01 \\
\hline Asian & $13(8.5-20)$ & $<0.001$ \\
\hline Other non-English-speaking & $1.7(1.2-2.5)$ & 0.003 \\
\hline \multicolumn{3}{|c|}{ Readmission } \\
\hline \multicolumn{3}{|c|}{ Known readmission versus one admission } \\
\hline Non-Indigenous Australian & 1 & \\
\hline Indigenous Australian & $1.6(1.0-2.4)$ & 0.03 \\
\hline Asian & $1.0(0.73-1.4)$ & 0.93 \\
\hline Other non-English-speaking & $1.2(0.77-1.8)$ & 0.44 \\
\hline \multicolumn{3}{|c|}{ Possible readmission versus one admission } \\
\hline Non-Indigenous Australian & 1 & \\
\hline Indigenous Australian & $1.8(1.1-2.8)$ & 0.02 \\
\hline Asian & $1.1(0.78-1.7)$ & 0.49 \\
\hline Other non-English-speaking & $1.8(1.1-2.8)$ & 0.01 \\
\hline
\end{tabular}

* Relative risk ratios from multinomial logistic regression models.

The Indigenous group was over-represented in both known and possible readmission groups. Conversely, the Asian and nonIndigenous Australian groups had similar readmission levels.

\section{DISCUSSION}

Almost three thousand young offenders were included in the study, of whom 143 (5\%) had died by a median of 6 years of follow-up, when the mean age of the cohort was 24 years. The overall mortality rate was 7.2 deaths per 1000 PYO, compared with 0.5 deaths per 1000 PYO for the equivalent Victorian population between 1988 and 1999 (see erratum for reference 1). Leading causes of death were drug-related, suicide and non-intentional injury, with death rates per 1000 PYO of 3.3, 1.7 and 1.5 , respectively. Again, this is well in excess of the equivalent Victorian population. ${ }^{1}$ Death was predicted by younger age at admission to custody, repeat admissions, extensive movement within the juvenile justice system (possible readmission) and drug-related offences.

Detention rates of juveniles in Victoria are considerably lower than those in any other jurisdiction in Australia, ${ }^{9}$ suggesting that our mortality estimates may not generalise to other jurisdictions. Nor will the findings be representative of most young offenders, who generally receive less intensive, community-based orders rather than detention. Our study invites a national data-matching study to identify interjurisdictional consist- encies and discrepancies in patterns of offending and mortality. That we did not find an association between offence profile and mortality is unexpected, and may be inconsistent with a recent United Kingdom report of self-inflicted deaths among prisoners in England and Wales in 1999-2000. ${ }^{17} \mathrm{~A}$ possible reason was that that study used a less strict definition of suicide, which included "probable suicide" classified by clinical consensus. The authors reported that 41 of 172 prisoners who were deemed to have committed suicide had been charged with or convicted of a violent offence.

Potential limitations of our study include possible incorrect specification of death owing to incorrect or missed matches. Only high-probability matches provided by the National Death Index were accepted after considering identifying data, making it unlikely that offender deaths were overcounted. Measurements other than death were limited to the period of cohort identification (1988-1999), while deaths were ascertained for a further three and a quarter years. Thus, further admissions and offences between 1999 and end of follow-up would have been missed for offenders under 21 years. Assessment of ethnicity varied between data sources, with juvenile justice clients $(72 \%$ of cohort entrants in the relevant 1996-1999 period) reporting the ethnicity they identified with, while adult corrections clients reported country of birth. These classification problems may have resulted in some mis-specification and attenuation of observed associations. Repeat custodial sentences may have been underspecified, but, as patterns of risk associated with "known" and "probable" readmissions were similar, this is unlikely to have substantively affected our conclusions.

Our findings confirm an earlier suggestion that early detention and repeat admissions mark ongoing risk of early unnatural death, ${ }^{18}$ especially from non-intentional injury. Individuals detained in a juvenile justice facility in Victoria have typically had recurrent contact with the legal system, often resulting in multiple, earlier non-custodial sentences. ${ }^{19}$ Those who continued a criminal career as adults are more likely to have been younger at first detention, ${ }^{20}$ and to be from disadvantaged backgrounds with endemic violence, neglect and a family predisposition to mental disorder. ${ }^{2}$ Such backgrounds are also common among those who later go on to develop antisocial personality disorder, ${ }^{21}$ a mental disorder itself associ- 
ated with an increased risk of early unnatural death. ${ }^{22}$

We were unable to assess direct indicators of mental health in our cohort, but the elevated suicide rates, ${ }^{1}$ based on the coroner's assessment of intent, implies that mental illness may have contributed. ${ }^{12}$ Substance misuse is clearly implicated, as indicated by the elevated risk of death associated with drug-related offences.

\section{Culturally related social marginalisation}

Incomplete data collection before 1996 of ethnic and Indigenous status resulted in insufficient power for us to examine its relevance directly, beyond identifying that Asian offenders were at increased risk of substance-related death. However, in the subcohort with admissions between 1996 and 1999, Indigenous offenders were overrepresented (13\% of $11-17$-year-olds in the cohort, compared with $0.9 \%$ in Victorian 0 17 -year-olds ${ }^{23}$ ). Although Indigenous offenders did not appear to have a higher death rate than non-Indigenous Australians, we observed admissions at a younger age, and more readmissions, consistent with early-life ${ }^{3}$ and transgenerational ${ }^{11}$ disadvantage. Young Indigenous offenders may therefore be at higher risk of death due to higher rates of early disadvantage. Although speculative, this suggestion is consistent with the recent report of a considerably lower survival rate for Western Australian Indigenous adult prisoners post-release compared with non-Indigenous prisoners. ${ }^{24}$

The Asian subgroup was more likely to be older at first admission, to have been convicted of a drug-related offence than all other offenders, and to be at greater risk of death from drug-related causes, thus not apparently conforming to the general pattern. Opiate dependence may directly account for the association, although community rejection, social marginalisation and alienation may play a further role.

\section{Summary}

Young offenders are over-represented in premature death statistics, with $25 \%$ of Victo- rian drug-related deaths in males aged 1519 years believed to occur in this group. ${ }^{1}$ Early custodial sentence, multiple detentions and drug-related offences are indicators of high mortality risk. These findings provide a strong rationale for continuing to treat mental disorders and substance misuse beyond the offender's custodial sentence, in partnership with community agencies, and in a way that takes account of cultural factors.

\section{ACKNOWLEDGEMENTS}

This study was funded by the National Health and Medical Research Council through the Competing Standard Project Grant 105422; the NHMRC had no role in study design, conduct or interpretation. We would like to thank Professor lan Anderson for his comments on the article.

\section{COMPETING INTERESTS}

None identified.

\section{REFERENCES}

1 Coffey C, Veit F, Wolfe R, et al. Mortality in young offenders: retrospective cohort study. BMJ 2003; 326: 1064-1067.

2 O'Shaughnessy RJ. Clinical aspects of forensic assessment of juvenile offenders. Psychiatr Clin North Am 1992; 15: 721-735.

3 Stewart A, Dennison S, Waterson E. Pathways from child maltreatment to juvenile offending. Griffith: School of Criminology and Criminal Justice, Griffith University, 2002.

4 Carr MB, Vandiver TA. Risk and protective factors among youth offenders. Adolescence 2001; 36: 409-426.

5 Beyers JM, Loeber R. Untangling developmental relations between depressed mood and delinquency in male adolescents. J Abnorm Child Psychol 2003; 31: 247-266.

6 Teplin LA, Abram KM, McClelland GM, et al. Psychiatric disorders in youth in juvenile detention. Arch Gen Psychiatry 2002; 59: 1133-1143.

7 Kosky RJ, Sawyer MG, Fotheringham M. The mental health status of adolescents released from custody: a preliminary study. Aust N Z J Psychiatry 1996; 30: 326-331.

8 Fasher AM, Dunbar N, Rothenbury BA, et al. The health of a group of young Australians in a New South Wales juvenile justice centre: a pilot study. J Paediatr Child Health 1997; 33: 426429.
9 Bareja M, Charlton K. Statistics on juvenile detention in Australia: 1981-2002, Technical and Background Paper Series, no. 5. Canberra: Australian Institute of Criminology; 2003.

10 Beyer L, Reid G, Crofts N. Ethnic based differences in drug offending. Aust N Z J Criminology 2001; 34: 169-181.

11 Anderson I. Understanding Indigenous violence. Aust N Z J Public Health 2002; 26: 408409.

12 Cavanagh JT, Carson AJ, Sharpe M, et al. Psychological autopsy studies of suicide: a systematic review. Psychol Med 2003; 33: 395-405.

$13 \mathrm{WHO}$. The international classification of diseases, 9th revision, clinical modification. 2nd ed. Washington, DC: US Dept of Health and Human Services; 1980.

14 WHO. International statistical classification of diseases and related health problems, 10th revision. 10th ed. Geneva: World Health Organization; 1992.

15 Australian Bureau of Statistics. 1234.0 Australian standard offence classification. Canberra: ABS, 1997

16 Stata. Stata statistical software: release 8 [computer program]. College Station, Tx: Stata Corporation, 2003.

17 Shaw J, Baker D, Hunt IM, et al. Suicide by prisoners: national clinical survey. Br J Psychiatry 2004; 184: 263-267.

18 Stattin H, Romelsjo A. Adult mortality in the light of criminality, substance abuse, and behavioural and family-risk factors in adolescence. Crim Behav Ment Health 1995; 5: 279311.

19 Harris R. Recidivism among Victorian juvenile justice clients 1997-2001. Melbourne: Department of Human Services; 2001.

20 Moffitt TE. Adolescence-limited and lifecourse-persistent antisocial behavior: a developmental taxonomy. Psychol Rev 1993; 100: 674-701.

21 Luntz BK, Widom CS. Antisocial personality disorder in abused and neglected children grown up. Am J Psychiatry 1994; 151: 670-674.

22 Martin RL, Cloninger CR, Guze SB, et al. Mortality in a follow-up of 500 psychiatric outpatients. II. Cause-specific mortality. Arch Gen Psychiatry 1985; 42: 58-66.

23 Australian Bureau of Statistics. 4119.0 Children, Australia: a social report. Canberra: ABS, 25 Feb 1999.

24 Stewart LM, Henderson CJ, Hobbs MST, et al. Risk of death in prisoners after release from jail. Aust N Z J Public Health 2004; 28: 32-36.

(Received 25 Mar 2004, accepted 2 Sep 2004) 